\title{
Determination of the type of repair work based on the results of survey and monitoring of the technical condition of buildings
}

\author{
Aleksandr Birjukov ${ }^{1}$, Anatoly Lebedkin ${ }^{1 *}$, Yurii Birjukov ${ }^{1}$, and Viktor Pchelkin ${ }^{1}$ \\ ${ }^{1}$ Military Academy of Logistics named Army General A.V. Chrulev, 8 nab. Makarova, St. \\ Petersburg, 199034, Russia
}

\begin{abstract}
This article is devoted to structural scrutiny of a building. The technical condition of buildings affects such characteristics of a building as safety, reliability, durability and maintainability. However, in the absence of reliable information on the technical condition of buildings, structural survey or monitoring of a building in order to determine the category of technical condition is necessary. The purpose of this work is to develop an economic and mathematical model for determining the type of maintenance work based on the results of structural scrutiny and monitoring of a building. The article is of importance because the final stage of the survey gives a qualified opinion on the level of structural scrutiny of a building, and on the basis of this opinion repair work eliminating physical and moral deterioration and providing in accordance with specifications renovation of the building are planned. The scientific novelty of the economic and mathematical model developed by the authors on the results of building structural scrutiny lies in the application of the fuzzy set theory and fuzzy logic method for determining of the level of physical and moral deterioration of a building consistent with a certain type of repair work and followed by the necessary capital investments.
\end{abstract}

\section{Introduction}

The technical condition of the building as a whole is a function of the serviceability of individual structural elements and the connections between them. The main factors affecting the serviceability of the building are:

- internal factors (physic and chemical processes occurring in the materials of construction; loads and processes during the operation; constructive ones);

- external factors (climatic (temperature, humidity, solar radiation); nature of the environment (wind, dust, biological factors); quality of operation).

For a more accurate determination of the technical condition of buildings with the account of the limits of their change during operation, it is necessary to conduct survey and monitoring. The need for a survey and monitoring of the technical condition of buildings is caused by physical deterioration and moral deterioration of building structures, changes in

*Corresponding author: lebedkin.86@bk.ru 
operating conditions as well as the lack of building codes in the explicit form of time factor.

The final stage of the technical condition monitoring of buildings is to obtain data on their actual condition. The data obtained as a result of monitoring is used to make an informed decision on the expediency of using the building with the subsequent determination of the necessary repair aimed at reinforcement or restoration of building structures.

The concept of 'repair work' includes current maintenance, major repairs and reconstruction [1, 2 and 3].

Repair work is carried out in order to prevent emergency situations, the destruction of building structures as well as to increase the accident - free operation of buildings. It should be noted that when performing a certain type of repair work, various organizational and technological solutions are made to eliminate the identified defects and deviations in order to return the building to a standard and operational condition [4, 5 and 6$]$.

The main criteria for the effectiveness of repair work on buildings can be time and cost (the restoration cost of a building) criteria as well as organizational and technological indicators [7, 8, 9, 10 and 11].

The restoration cost of a building means the elimination of physical and moral deterioration and bringing the building into a standard technical condition [12, 13, 14 and $15]$.

The authors analyzed the regulatory documents and scientific works in the field of using technique and methods for determining (estimating) the cost of building restoration [13, 14, 15 and 16]. As a result of the analysis, it was determined that central failures in the cost of calculation of restoration of a building are the following:

the category of the technical condition of buildings is not always taken into account; the combined values of physical and moral depreciation is not taken into account; the cost of repair work aimed at increasing the operational life of the building is not taken into account; It requires a large amount of detailed and reliable information about the surveyed building as well as detailed information on the composition and time of repair work (reconstruction) that is often difficult.

One of the most important tasks in planning repair work of a building is to determine the financial costs (restoration cost) for these works. Determining the restoration cost of a building is complicated by the fact that many of the input data required for the calculations are vague and not fully defined. The latter circumstance is explained by the mass of various factors affecting the physical and moral deterioration of buildings and their impact is rather mixed. To solve this uncertainty in the initial data, the authors propose to use elements of the theory of fuzzy sets and fuzzy logic.

\section{Materials and Methods}

The concept of fuzzy set - this attempt of mathematical formalization of fuzzy information to build mathematical models. This concept is based on the idea that the elements constituting a given set, and having a common property, may have this property to various degrees and, therefore, belong to this set with different degrees. Saying under this approach, that a certain element belongs to a given set, it is necessary to indicate to what degree this element satisfies the properties of the given set.

Systems and processes based on fuzzy sets have been developed and implemented successfully in various areas such as technological management, transport management, medical diagnostics, technical diagnostics, financial management and stock exchange forecasting.

Using the theory of fuzzy sets and fuzzy logic the authors of the article developed an economic and mathematical choice model of repair work based on the results of the survey and monitoring of the technical condition of a building. 
The fuzzy set Ân the universal set $U$ is the set of $\operatorname{pairs}\left(\mu_{\widehat{A}}(u), u\right)$, where $\mu_{\widehat{A}}(u)$ is the membership function which indicates the degree of membership of an arbitrary element $\left(\mu_{\widehat{A}}(u)\right.$ or $u$ ) of the universal set $U$ to fuzzy set $\widehat{A}$.

The intersection of fuzzy sets $\widetilde{A}$ and $\widetilde{B}$ defined on $U$ is called a fuzzy set $\widetilde{C}=\widetilde{A} \cap \widetilde{B}$ with the membership function $\mu_{\widehat{C}}(u)=\min \left\{\mu_{\widehat{A}}(u), \mu_{\widehat{B}}(u)\right\}$ for all $u \in U$.

The union of fuzzy sets $\widetilde{A}$ and $\widetilde{B}$ defined on $U$ is called a fuzzy set $D=\widetilde{A} \cup \widetilde{B}$ with the membership function $\mu_{\widehat{D}}(\mathrm{u})=\max \left\{\mu_{\widehat{\mathrm{A}}}(\mathrm{u}), \mu_{\widehat{\mathrm{B}}}(\mathrm{u})\right\}$ for all $\mathrm{u} \in \mathrm{U}$.

Following [17 and 18], we introduce some concepts of fuzzy logic. In classical mathematical logic, the truth values of statements can be only two values - "true" and "false" while the value "true" corresponds to the number 1 , the value "false" - the number 0 . In fuzzy logic, fuzzy statements are considered that can be true or false to some extent (with some reliability). The degree of truth of a fuzzy utterance takes values from a closed interval [0: 1], while 0 coincides with the value "false", 1 - with the value "true". In this paper, we will consider variable fuzzy statements $\widetilde{A}\left(u_{1}, u_{2}, \ldots, u_{r}\right)$, that is, statements that depend on some arguments $\mathrm{u}_{1}, \mathrm{u}_{2}, \ldots, \mathrm{u}_{\mathrm{r}}$ and become fuzzy statements for a fixed value of these arguments. The degree of truth (with a given reliability) of a fuzzy utterance takes values on the interval [0-1], while 0 coincides with the value "false", 1 - with the value "true". When performing calculations, variables are considered fuzzy statements $\widetilde{A}\left(u_{1}, u_{2}, \ldots, u_{r}\right)$, i.e. statements that depend on some arguments $\mathrm{u}_{1}, \mathrm{u}_{2}, \ldots, \mathrm{u}_{\mathrm{r}}$ and become fuzzy statements for a fixed value of these arguments. The degree of truth of a fuzzy utterance $\widetilde{A}\left(u_{1}, u_{2}, \ldots, u_{r}\right)$ is denotedby $\mu_{\widetilde{A}}\left(u_{1}, u_{2}, \ldots, u_{r}\right)$.

Thus, variables of fuzzy statements (hereinafter - fuzzy statements) are formalized using fuzzy sets.

Various logical operations are introduced over fuzzy statements. Fuzzy logical operations AND $(\wedge)$ and $\mathrm{OR}(\vee)$ by analogy with the set-theoretic union and intersection operations are performed according to the rules:

$$
\begin{aligned}
& \mu_{\tilde{A} \vee \tilde{B}}(u)=\min \left\{\mu_{\tilde{A}}(u), \mu_{\tilde{B}}(u)\right\}, \\
& \mu_{\tilde{A} \vee \tilde{B}}(u)=\max \left\{\mu_{\tilde{A}}(u), \mu_{\tilde{B}}(u)\right\} .
\end{aligned}
$$

The concept of a linguistic variable is introduced in fuzzy logic.

A linguistic variable is a variable with values in words or phrases of some natural or artificial languages.

A term set is a set of all possible values of a linguistic variable. A term is any element of a term set. In the theory of fuzzy sets a term is formalized by a fuzzy set using the membership function. The membership function of a fuzzy set formalizes a fuzzy term $\mathrm{F}$ defined on the universal set $\mathrm{U}$ by $\mu_{\mathrm{F}}(\mathrm{u}), \mathrm{u} \in \mathrm{U}$.

The number of terms is recommended (see, for example, [27]) no more than 5 - 9.

Quite often, terms are formalized with the help of trapezoidal and triangular fuzzy numbers.

The trapezoid fuzzy number $\mathrm{A}$ is the quadruple $(a, b, c, d) a \leq b=c \leq d$ real numbers through which its membership function $\mu_{\mathrm{A}}$ is defined as follows (figure 1):

$$
\mu_{A}(u)=\left\{\begin{array}{c}
(u-a) /(b-a), \text { if a } u \in[a, b] ; \\
1, \text { if } \mathrm{a} u \in[b, c] ; \\
(u-d) /(c-d), \text { if a } u \in[c, d] ; \\
0, \text { otherwise. }
\end{array}\right.
$$

If $\mathrm{b}=\mathrm{c}$, then we get a triangular fuzzy number. 


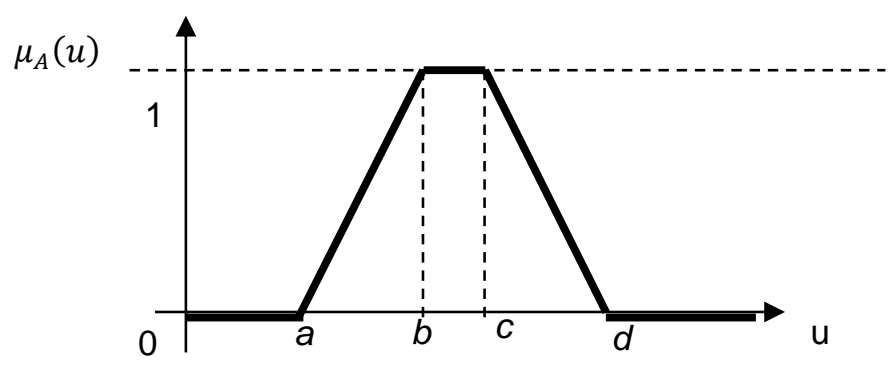

Fig. 1. An example of the graph of the membership function of a trapezoidal fuzzy number

Figures $2 \mathrm{a}, 2 \mathrm{~b}$ and $2 \mathrm{c}$ show examples of graphs of the membership functions of triangular fuzzy numbers, on which the whole numerical axis is the universal set.

For example, Figure 2a shows the graph of the membership function of a fuzzy triangular number $A=(a, b, c)$ which can be linguistically interpreted as "about b" or "approximately $\mathrm{b}$ ". The second number $b$ of a triple $(a, b, c)$ is usually called a mode or a clear value of a fuzzy triangular number. The numbers $a$ and $c$ characterize the degree of blur (fuzziness) of a clear number $b$.

It should be noted that none of the denominators in formula (3) is considered to be equal to zero. If $a=b(c=d)$, then we get situations similar to the situations depicted in Figures $2 \mathrm{~b}$ and $2 \mathrm{c}$.

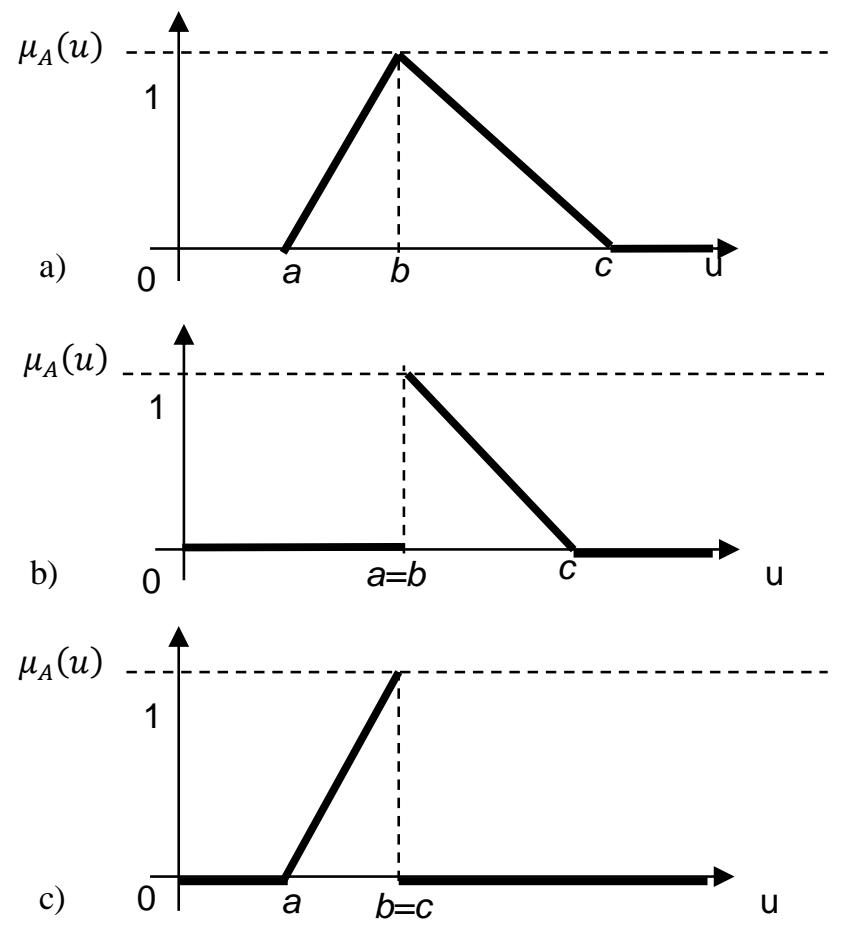

Fig. 2 (a, b, c). Triangular number

An important role in solving the problem of planning, evaluation, management is the task in which, according to a given set (vector) $\mathrm{X}=\left(\mathrm{x}_{1}, \mathrm{x}_{2}, \cdots, \mathrm{x}_{\mathrm{n}}\right)$ of the factor values (input variables), determine the value of the parameter (output variable) $y$. 
A fuzzy knowledge base about the effect of a given set of values of the factors $X=\left\{x_{1}, x_{2}, \cdots, x_{n}\right\}$ on the value of the parameter $\mathrm{y}$ is called a set of logical statements like:

$$
\begin{aligned}
& \operatorname{IF}\left(x_{1}=a_{1}^{j_{1}^{1}}\right) \text { and }\left(x_{2}=a_{2}^{j_{2}^{1}}\right) \text { and } \ldots \text { and }\left(x_{n}=a_{n}^{j_{n}^{1}}\right) \text {; } \\
& \operatorname{OR}\left(x_{1}=a_{1}^{j_{1}^{2}}\right) \text { and }\left(x_{2}=a_{2}^{j_{2}^{2}}\right) \text { and } \ldots \text { and }\left(x_{n}=a_{n}^{j_{n}^{2}}\right) \text {; } \\
& \text { OR } \\
& \operatorname{OR}\left(x_{1}=a_{1}^{j_{1} k_{j}}\right) \text { and }\left(x_{2}=a_{2}^{j_{2} k_{j}}\right) \text { and } \ldots \text { and }\left(x_{n}=a_{n}^{j_{n}^{k_{j}}}\right) \text {, that } y(X)=d_{j} \text {. }
\end{aligned}
$$

where $a_{i}^{j_{i}^{p}}$ is a fuzzy term by which the variable $x_{i}$ is estimated in the line with the number $p\left(p=\overline{1, k_{j}}\right), ; j_{i}^{p}$ is the ordinal number of this term in the term set of the linguistic variable with the number $i, j_{i}^{p} \in\left\{1,2, \ldots, r_{i}\right\}, r_{i}$-is the number of elements in this term set; $k_{j}$ - the number of lines-conjunctions, in which the output $y(x)$ is estimated by a fuzzy term $d_{j}, j=$ $1,2, \ldots, m ; m$ is the number of terms used for linguistic estimation of the output parameter $y$ using the operations $\vee(\mathrm{OR})$ and $\wedge$ (AND).

For further data processing you will need a simplified fuzzy knowledge base consisting of lines each of them containing two statements and each statements containing a conjunction. It is often convenient to set in the form of a table.

Example. Let us consider a fuzzy knowledge base given by Table 1.

Table 1. Fuzzy knowledge base of fuzzy terms of the output variable

\begin{tabular}{|c|c|c|c|c|}
\hline \multirow{2}{*}{$\begin{array}{l}\text { Terms of the first } \\
\text { linguistic variable }\end{array}$} & \multicolumn{4}{|l}{$\begin{array}{l}\text { Terms of the second linguistic } \\
\text { variable }\end{array}$} \\
\cline { 2 - 5 } & $a_{1}^{2}$ & $a_{2}^{2}$ & $a_{3}^{2}$ & $a_{4}^{2}$ \\
\hline$a_{1}^{1}$ & $d_{2}$ & $d_{3}$ & $d_{3}$ & $d_{2}$ \\
\hline$a_{1}^{2}$ & $d_{4}$ & $d_{1}$ & $d_{5}$ & $d_{2}$ \\
\hline$a_{3}^{1}$ & $d_{1}$ & $d_{3}$ & $d_{2}$ & $d_{1}$ \\
\hline
\end{tabular}

In accordance with this fuzzy knowledge base (Table 1), a logical statement, the consequence of which is the term $d_{3}$, takes the form:

IF a $\left(x_{1}=a_{1}^{1}\right) \operatorname{and}\left(x_{2}=a_{3}^{2}\right)$; OR $\left(x_{1}=a_{3}^{1}\right)$ and $\left(x_{2}=a_{2}^{2}\right)$; OR $\left(x_{1}=a_{1}^{1}\right) \operatorname{and}\left(x_{2}=\right.$ $a_{2}^{2}$ ), that $y(X)=d_{3}$.

The membership function of a fuzzy set, formalizing the output term (index term) $d_{j}$ is denoted by $\mu_{d_{j}}(u)$. Its values are determined by the formula (3) with the corresponding term $d_{j}$ values of numbers $a, b, c$.

The membership function of a fuzzy set $\left(y(X)=d_{j}\right.$ provided that the set of values of the input variables (parameters) is $X$ ) will be denoted by $\bar{\mu}_{d_{j}}(X)$. It should be noted that the universal set on which this function is defined it is the set of all possible sets of factor values. The formulas (1) and (2) imply:

$$
\bar{\mu}_{d_{j}}(X)=\max _{1 \leq p \leq k_{j}}\left[\min _{1 \leq i \leq n} \mu_{a_{i} j_{i}^{p}}\left(x_{i}\right)\right],
$$

The membership function $\mu_{y, X}(u)$ fuzzy set (the value of the output variable $y$ at a set of values of factors $X$ ) is determined by the formula:

$$
\mu_{y, X}(u)=\max _{1 \leq j \leq m} \min \left\{\bar{\mu}_{d_{j}}(X), \mu_{d_{j}}(u)\right\} .
$$

To solve the problem, we first consider three linguistic variables - two inputs and one output. It should be noted that the problem is a vector optimization with fuzzy input data.

The input linguistic variables for determining the type of repair work of a building are set 
as follows:

the value of the obsolescence of a building is given by the terms "little", "average", "much" and "very much". These terms with input fuzzy X are formalized by fuzzy sets defined on the universal set $Y=[0 \%-100 \%]$. The graphs of the membership functions of these terms (fuzzy sets that formalize them) are presented in figure $3 \mathrm{a}$;

the value of physical deterioration of a building is given by the terms "very little", "average", "much" and "very much". These terms are formalized by fuzzy sets defined on the universal set $X=[0 \%-100 \%]$. The graphs of the membership functions of these terms (fuzzy sets that formalize them) are presented in figure $3 \mathrm{~b}$.

The output linguistic variable in determining the type of repair work is "the restoration cost of a building" (in \%) with the terms of "current repairs", "major repairs", "reconstruction" and "new construction". These terms are formalized by fuzzy sets defined on a universal set $Z=[0 \%-100 \%]$. The graphs of the membership functions of the terms of the restoration cost of a building (in \%) (fuzzy sets that formalize them) are presented in figure $3 \mathrm{c}$.
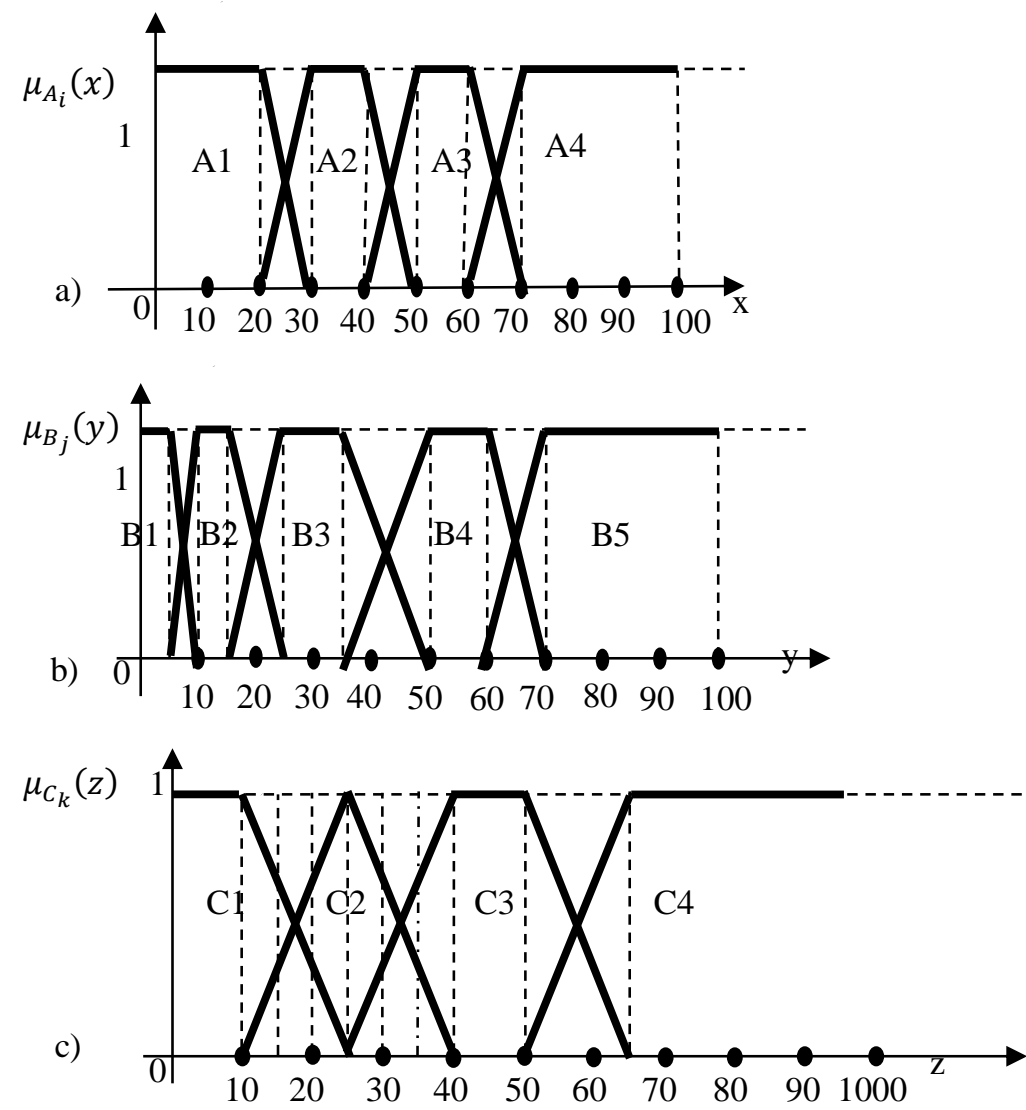

Fig. 3. a) Graph of the membership function of the obsolescence;. b) Graph of the membership function of the physical deterioration; c) Graph of the membership function of the restoration

Let us define a fuzzy knowledge base to determine the type of repair work and its restoration cost for a building in Table 2. At the intersection of the line of the input linguistic variable of "obsolescence" and the column of the input linguistic variable of physical deterioration the output linguistic variable of the restoration cost of a building (in \%) with the terms of the corresponding type of repair work such as "current repairs", "major repairs", 
"reconstruction", "demolition" and "new construction" is determined.

Table 2. Fuzzy knowledge base for determining the type of repair work

\begin{tabular}{|c|c|c|c|c|c|}
\hline \multirow{2}{*}{$\begin{array}{l}\text { obsolescenc } \\
\mathrm{e}\end{array}$} & \multicolumn{5}{|c|}{ Physical deterioration } \\
\hline & very little & little & average & much & very much \\
\hline little & $\begin{array}{l}\text { current } \\
\text { repairs }\end{array}$ & $\begin{array}{l}\text { current } \\
\text { repairs }\end{array}$ & $\begin{array}{l}\text { major } \\
\text { repairs }\end{array}$ & reconstruction & $\begin{array}{l}\text { Demolition and } \\
\text { new construction }\end{array}$ \\
\hline average & $\begin{array}{l}\text { current } \\
\text { repairs }\end{array}$ & $\begin{array}{l}\text { major } \\
\text { repairs }\end{array}$ & $\begin{array}{l}\text { major } \\
\text { repairs }\end{array}$ & reconstruction & $\begin{array}{l}\text { Demolition and } \\
\text { new construction }\end{array}$ \\
\hline much & $\begin{array}{l}\text { major } \\
\text { repairs }\end{array}$ & $\begin{array}{l}\text { major } \\
\text { repairs }\end{array}$ & reconstruction & reconstruction & $\begin{array}{l}\text { Demolition and } \\
\text { new construction }\end{array}$ \\
\hline very much & $\begin{array}{l}\text { major } \\
\text { repairs }\end{array}$ & reconstruction & reconstruction & $\begin{array}{l}\text { Demolition and } \\
\text { new construction }\end{array}$ & $\begin{array}{l}\text { Demolition and } \\
\text { new construction }\end{array}$ \\
\hline
\end{tabular}

We introduce the notation for the input linguistic variables and the output linguistic variable when determining the type of repair work of the output term of the replacement value of the building.

The linguistic variable of "obsolescence" is denoted by $A$ and its term "little" is $A_{1}$, "average" is $A_{2}$, "much" is $A_{3}$ and "very much" is $A_{4}$ (figure $3 \mathrm{a}$ ).

The linguistic variable of "physical deterioration" is denoted by $B$ and its term "very little" is $B_{1}$, term "little", $-B_{2}$, "average" is $B_{3}$, "much" is $B_{4}$, and "very much" is $B_{5}$ (figure $3 \mathrm{~b}$ ).

The linguistic variable of "the restoration cost of a building" (\%) is denoted by $C$ and its term "current repairs" is $C_{1}$, "major repairs" is $C_{2}$, "reconstruction" is $C_{3}$, "construction" is $C_{4}$ (figure $3 \mathrm{c}$ ).

It is assumed that $E_{i j}(i=1,2,3,4, j=1,2,3,4,5)$ is anunclear statement (situation).

$\left[\right.$ "obsolescence" $=A_{i}$ AND "physical deterioration"= $\left.B_{j}\right]$. The membership function` of this fuzzy utterance for given values $x$ and $y$ input parameters is denoted by $\mu_{i j}(x, y)$. The results obtained with the accepted symbols are given in Table 3.

Table 3. The knowledge base in the accepted notation for determining the type of repair work

\begin{tabular}{|c|c|c|c|c|c|}
\hline \multirow{2}{*}{ obsolescence } & \multicolumn{5}{|c|}{ Physical deterioration } \\
\cline { 2 - 6 } & $B_{1}$ & $B_{2}$ & $B_{3}$ & $B_{4}$ & $B_{5}$ \\
\hline$A_{1}$ & $E_{11}$ & $A_{12}$ & $E_{13}$ & $A_{14}$ & $E_{15}$ \\
\hline$A_{2}$ & $E_{21}$ & $A_{22}$ & $E_{23}$ & $A_{24}$ & $E_{25}$ \\
\hline$A_{3}$ & $E_{31}$ & $A_{32}$ & $E_{33}$ & $A_{34}$ & $E_{35}$ \\
\hline$A_{4}$ & $E_{41}$ & $A_{42}$ & $E_{43}$ & $A_{44}$ & $E_{45}$ \\
\hline
\end{tabular}

Let us denote the value of the membership function of a fuzzy set by $\mu_{A_{i}}(x)$ that formalizes a term $A_{i}$ with equal $x$ as the value of the linguistic variable of "obsolescence".

Through $\mu_{B_{j}}(y)$ we denote the value of the membership function of a fuzzy set that formalizes the term $B_{j}$ with equalyas the value of the linguistic variable of "physical deterioration".

Through $\mu_{C_{k}}(z)$ we denote the value of the membership function of a fuzzy set that formalizes the term $C_{k}$ with equal $\mathrm{z}$ as the value of the linguistic variable of "the restoration cost".

To determine the degree of the repair work type with the output variable of "the restoration cost of a building" (in \%) we introduce the following notation:

$\mu_{i j k}(x, y, z)$ - themembership function of a fuzzy utterance [(term value $A_{i}$ is equal to $x$ ) AND [(term value $B_{j}$ equally $\left.y\right)$ ] AND [(term value $C_{k}$ equally $z$ )] as a result of the actions performed we obtain the expression: 


$$
\mu_{i j k}(x, y, z)=\min \left\{\mu_{A_{i}}(x), \mu_{B_{j}}(y), \mu_{C_{k}}(z)\right\}=\min \left\{\mu_{i j}(x, y), \mu_{C_{k}}(z)\right\}
$$

where: $\mu_{C}(x, y, z)$ - the membership function of the type of repair work of the linguistic variable of "the restoration cost of a building" (\%) provided that the input variables are respectively equal to $x$ and $y$. That is: $\mu_{C}(x, y, z)$ - the membership function of a fuzzy utterance (the value of the output variable of "the restoration cost of a building" provided that the input variables are equal to $x$ and $y$ and the expenses are equal to $z$ ) represented by the formula:

$$
\mu_{C}(x, y, z)=\max _{i, j, k} \mu_{i j k}(x, y, z) .
$$

Furthermore, "the restoration cost of a building" (in \%) is determined on the basis of dephasing the probability of the building restoration by carrying out an appropriate type of repair work. Dephasing of the constructed fuzzy set function $\mu_{i j k}(x, y, z)$ of a fuzzy utterance membership function and the membership function of a linguistic variable $\mu_{C}(x, y, z)$ are determined by the method of "center of gravity" (like the expected value in calculus of probability and center of gravity in mechanics) and represented by the formula:

$$
K_{s v}=\frac{\sum_{z=5}^{100}\left(\mu_{i j k}(x, y, z) \cdot z\right)}{\sum_{z=5}^{100} \max \left\{\mu_{C}(x, y, z)\right\}}
$$

where: $K_{v s}$ - "the restoration cost of a building" - \%;

$\mathrm{z}$ - "the restoration cost step", $\%$ in the interval [0\%-100\%];

$\mu_{i j k}(x, y, z)-$ the value of the membership function of a fuzzy statement of the type of repair work [0-1] from "the restoration cost of" an object with increment of step $\Delta z$;

$\mu_{C}(x, y, z)$ - the maximum value of the membership function of the linguistic variable of the type of repair work [0-1] from "the restoration cost of an object" with increment of step $\Delta z$.

\section{Results}

Figure 4 shows the algorithm developed by the authors for determining the type of repair work on the basis of the developed economic and mathematical model that allows interpreting the results of the survey and monitoring of the technical condition of buildings. 


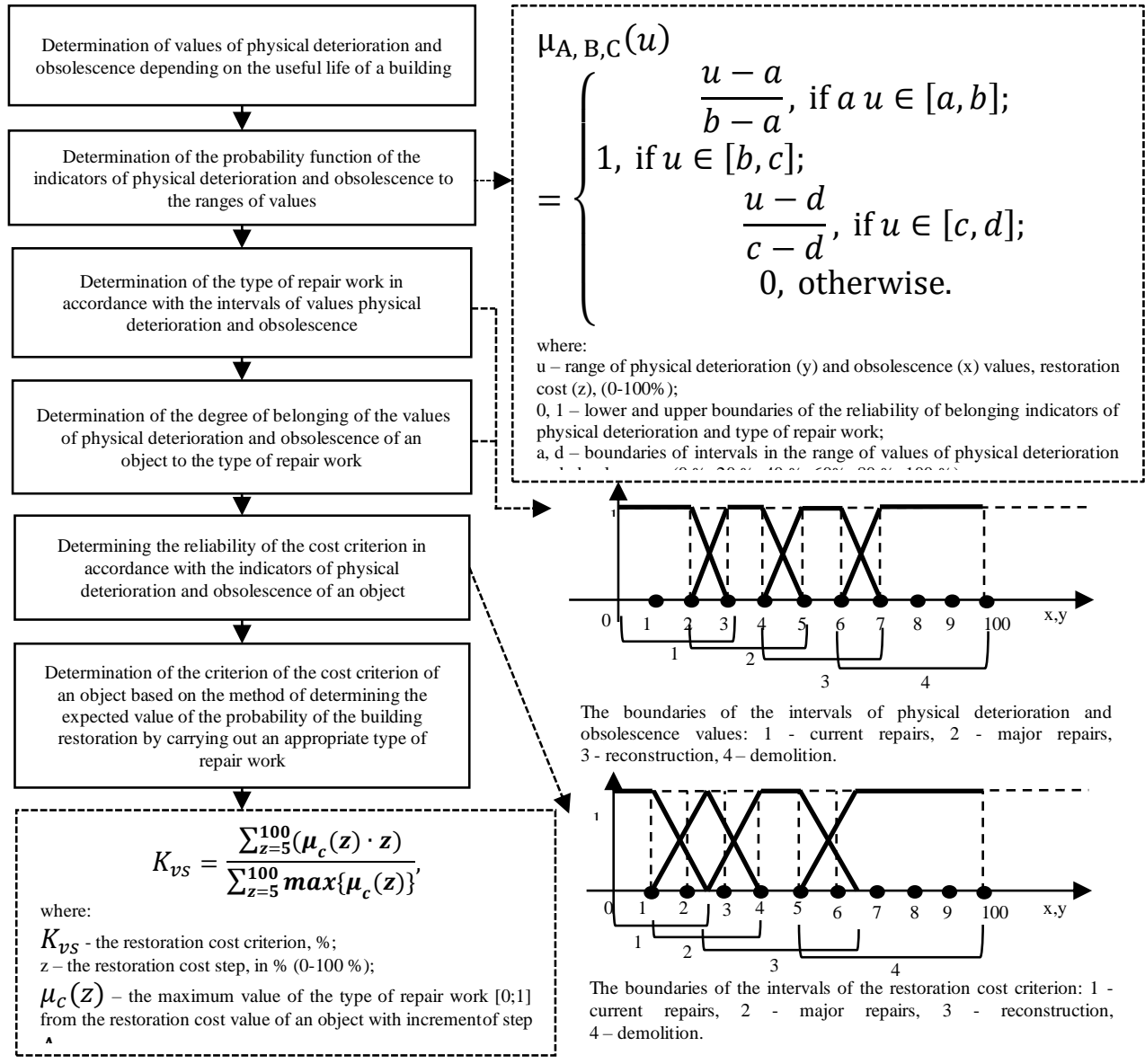

Fig. 4. Algorithm for determining the type of repair work based on the results of the survey and monitoring of the technical condition of buildings

\section{Discussion}

Under the application of the theory of fuzzy sets, the authors have developed an economicmathematical model for selecting the type of repair work based on the results of survey and monitoring of the technical condition of a building. This mathematical model makes it possible to efficiently select the type of repair work (current repair, major repair or reconstruction), and also to determine the necessary cost of such a work.

Currently, the choice of the type of repair work and the quality of their performance depends on the duration of trouble-free operation of buildings. In turn, the trouble-free operation of buildings significantly reduces the volume of capital investments aimed at their operation.

\section{Conclusions}

Consequently, the application of the economic and mathematical model developed by the authors increases the efficiency of use of data based on the results of structural scrutiny owing to improving of the assessment accuracy of the technical condition of the surveyed building 
by taking into account physical deterioration and obsolescence.

The use of an economic and mathematical model will allow for the scheduled repair of buildings that will reduce deterioration and increase the quality of the operational maintenance of buildings.

\section{References}

1. O.A. Korol, Journal of Physics: Conference Series, 1425, 012086, (2020) doi:10.1088/1742-6596/1425/1/012086

2. E. Degaev, R. Barkhi, Journal of Physics: Conference Series, 1425, 012066, (2020) doi:10.1088/1742-6596/1425/1/012066

3. V. Konyuhov, A. Gladkih, V. Semenov, Journal of Physics: Conference Series, 1353, 012046, (2019), doi:10.1088/1742-6596/1353/1/012046

4. M. Dement'eva, IOP Conference Series: Earth and Environmental Science, 90, 012052 , (2017) doi :10.1088/1755-1315/90/1/012052

5. E. Andenæs, A. Engebø, T. Kvande, R. A Bohne and J Lohne, IOP Conference Series: Earth and Environmental Science, 290, 012069, (2019) doi:10.1088/17551315/290/1/012069

6. D. Baiburin, A. Baiburin, IOP Conference Series: Materials Science and Engineering, 262, 012190, (2017) doi:10.1088/1757-899X/262/1/012190

7. M. Shutova, G. Skibin, S. Evtushenko, IOP Conference Series: Materials Science and Engineering, 262, 012061, (2017) doi:10.1088/1757-899X/262/1/012061

8. A. Adamtsevich, L. Shilova, IOP Conference Series: Earth and Environmental Science, 90, 012152, (2017) doi:10.1088/1755-1315/90/1/012152

9. A. Birjukov, E. Dobryshkin, I. Kravchenko and M. Glinskiy, Proceedings of the 18th International Scientific Conference Engineering for rural development, 18, (2019) doi:10.22616/ERDev2019.18.N505

10. A. Konikov, IOP Conference Series: Earth and Environmental Science, 403, 012223 , (2019) doi:10.1088/1755-1315/403/1/012223

11. J. Shchepochkina, M. Akulova, J. Sokolova, A. Sokolova, IOP Conference Series: Materials Science and Engineering, 661, 012105, (2019) doi:10.1088/1757899X/661/1/012105

12. K. Hellova, A. Struharova, IOP Conference Series: Materials Science and Engineering, 385, 012017, (2018) doi:10.1088/1757-899X/385/1/012017

13. S. Korniyenko, IOP Conference Series: Materials Science and Engineering, 463, 022060, (2018) doi:10.1088/1757-899X/463/2/022060

14. M. Dytczak, G. Ginda, Technological and Economic Development of Economy, 15, (2009) doi:10.3846/1392-8619.2009.15.213-228.

15. A. Mardani, A. Jusoh, et al., Economic Research-Ekonomska Istraživanja, 31, (2018), doi:10.1080/1331677X.2018.1488600

16. S. T. Moghadam, IOP Conference Series: Earth and Environmental Science, 297, 012041, (2019) doi:10.1088/1755-1315/297/1/012041

17. O. Antamoshkin, E. Bryukhanova, V. Antamoshkina, N. Pikov, V. Kukartsev and V. Tynchenko, Journal of Physics: Conference Series, 1399, 033103, (2019) doi:10.1088/1742-6596/1399/3/033103 
18. D. Gadjiev, I. Kochetkov and A. Rustanov, IOP Conference Series: Earth and Environmental Science, 403, 012187, (2019) doi:10.1088/1755-1315/403/1/012187 